\title{
Cerebrospinal Fluid Neurochemical Phenotypes in Vascular Dementias: Original Data and Mini-Review
}

\author{
Mirko Bibl $^{\mathrm{a}}$ Brit Mollenhauer ${ }^{\mathrm{b}}$ Hermann Esselmann $^{c}$ Michael Schneider ${ }^{\mathrm{d}}$ \\ Piotr Lewczuk ${ }^{c}$ Volker Welge ${ }^{e}$ Martin Gross ${ }^{f}$ Peter Falkai ${ }^{e}$ \\ Johannes Kornhuber ${ }^{c}$ Jens Wiltfang ${ }^{a}$ \\ ${ }^{a}$ Klinik für Psychiatrie und Psychotherapie der Rheinischen Kliniken Essen, Universität Duisburg-Essen, Essen, \\ b University of Göttingen, Paracelsus-Elena Klinik, Kassel, ' Department of Psychiatry and Psychotherapy, \\ University of Erlangen-Nuremberg, Erlangen, ' Zentralinstitut für Seelische Gesundheit, Department of Biostatistics, \\ Mannheim, e Department of Psychiatry, University of Göttingen, Göttingen, and fNeurologische Klinik Bad Aibling, \\ Bad Aibling, Germany
}

\section{Key Words}

Alzheimer's dementia $\cdot$ Vascular dementia $\cdot$ Cerebrospinal fluid $\cdot$ Amyloid- $\beta$ peptides $\cdot$ Biomarker

\section{Abstract}

Background/Aims: The study evaluated the patterns of cerebrospinal fluid (CSF), amyloid- $\beta$ (A $\beta$ ) peptides, total tau and phospho-tau among Alzheimer's disease (AD) and vascular dementias (VAD). Methods: A $\beta$-SDS-PAGE immunoblot and commercially available ELISAs were applied to the CSF analysis of 52 patients with probable $(n=21)$ and possible $(n=16)$ VAD, AD with cerebrovascular disease $(n=15)$, 30 patients with probable AD and 30 nondemented disease controls. Results: AD and AD with cerebrovascular disease displayed a similar neurochemical phenotype in contrast to nondemented disease controls and probable VAD with regard to tau, $\mathrm{p}$-tau, $A \beta 1-40^{\circ \mathrm{x}}$ and $A \beta 1-42 \%$. Possible VAD displayed $A D$-like changes only for $A \beta 1-40^{\circ}$ and $A \beta 1-42 \%$. Conclusion: CSF neurochemical phenotypes sufficiently discriminate probable AD and VAD from each other, but their diagnostic value is limited in case of no clear-cut clinical ap-

\section{KARGER}

Fax +41613061234

E-Mail karger@karger.ch

www.karger.com
(C) 2008 S. Karger AG, Basel

$1420-8008 / 08 / 0253-0256 \$ 24.50 / 0$

Accessible online at:

www.karger.com/dem pearance, such as possible VAD. Conversely, CSF A $\beta$ peptides and $p$-tau levels may help estimate the involvement of $A D$ like pathophysiological pathways in VAD subgroups.

Copyright $\odot 2008$ S. Karger AG, Basel

\section{Introduction}

Besides Alzheimer' disease (AD) and dementia with Lewy bodies, vascular dementias (VAD) are one of the most common forms of dementia in the elderly. VAD represents a syndrome of a large etiological heterogeneity and a broad spectrum of clinical appearance. The clinical discrimination between VAD and $\mathrm{AD}$ is a routine diagnostic challenge and often has a profound impact on the therapeutic strategy applied. Although clinical criteria have been established for VAD [1, 2] and $\mathrm{AD}[3]$ to aid this crucial question, there is still a large overlap of symptoms and courses of disease. Likewise, overlapping vascular lesions and $\mathrm{AD}$ pathology are frequent neuropathologic findings [4] and both factors may contribute to a progressive loss of cognitive functions. However, in case of ad- 
vanced $\mathrm{AD}$, the effects of $\mathrm{AD}$ pathology on the cognitive status seem to increasingly overcome the impact of vascular factors [5].

The 2 neuropathological hallmarks of AD are amyloid plaques and neurofibrillary tangles. Amyloid plaques mainly consist of carboxyterminally elongated forms of amyloid- $\beta(A \beta)$ peptides [6]. These peptides are cleaved from the transmembrane amyloid precursor protein by 2 enzymes, $\beta$ - and $\gamma$-secretase [7]. Distinct $\gamma$-secretase activities are hypothesized to be responsible for the generation of either carboxyterminally truncated or elongated $A \beta$ peptides as referenced to $A \beta 1-40$ [8]. The major constituent of neurofibrillary tangles is tau, a $68-\mathrm{kDa}$ microtubule-associated phosphoprotein that undergoes enhanced phosphorylation and aggregates into paired helical filaments in $\mathrm{AD}$ [9].

Biomarkers like $A \beta 1-42$, tau and phosphorylated tau have proved to be of debatable diagnostic value for the detection of $\mathrm{AD}$ among $\mathrm{VAD}[10]$. A $\beta$ peptides other than $A \beta 1-42$ have shown differential diagnostic value for $A D$ among other neurodegenerative disorders [11-14]. Here, we address the question whether $\mathrm{AD}$ and $\mathrm{VAD}$ of different clinical phenotypes may be characterized by distinct neurochemical phenotypes in cerebrospinal fluid (CSF).

\section{Patients and Methods}

A total of 112 consecutive CSF samples that had been referred to our laboratory between 2000 and 2004 from wards and the dementia outpatient clinic of the University of Göttingen and the University of Erlangen were prospectively investigated. The handling of CSF followed a standardized protocol according to previously published data [15]. The diagnosis was established by a neurologist and a psychiatrist, both very experienced in the clinical differential diagnosis of dementias. Both investigators were blinded to the neurochemical outcome measures. If possible, neuropsychological assessment, Mini-Mental State Examination (MMSE) according to Folstein et al. [16], was performed on patients suffering from cognitive impairments at the time of lumbar puncture.

Investigations were carried out with the informed consent of the patients or their next of kin. The study was conducted under the guidelines of the Declaration of Helsinki [17] and approved by the ethics committees of the Universities of Göttingen and Erlangen-Nuremberg.

\section{Patients}

We investigated 52 patients with VAD (20 men and 32 women) according to DSM IV and the NINDS-AIREN criteria [2]. The patients were further characterized by Hachinski's ischemic scale in its modified version according to Fischer et al. [18] and patients with a score less than 6 were excluded. All included patients exhibited typical signs of relevant cerebrovascular disease (CVD) in neuroimaging (computerized tomography, magnetic resonance imaging). Subtypes of VAD were determined in accordance with the NINDS-AIREN criteria [2] and with the classification of sporadic vascular impairment [19]. Twenty-one and 16 patients displayed the clinical course of probable and possible VAD, respectively. Patients with a CVD that fulfilled the criteria of NINCDSADRDA (National Institute of Neurological and Communicative Disorders and Stroke-Alzheimer's Disease and Related Disorders Association) for possible $\mathrm{AD}$ were classified as $\mathrm{AD}$ with $\mathrm{CVD}$ $(\mathrm{n}=15)$.

Thirty patients (11 men and 19 women) with probable AD according to DSM IV and the NINCDS-ADRDA criteria [3] were investigated for comparison. AD patients displayed no signs of relevant CVD in either computerized tomography or magnetic resonance imaging, except for mild white matter lesions.

The 30 nondemented disease controls (NDC) (14 men and 16 women) comprised 15 patients suffering from depression, and 8 patients with peripheral and 7 with central neurological diseases. In detail, peripheral neurological patients were diagnosed as having polyneuropathy $(n=3)$ and peripheral facial nerve palsy $(n=$ $3)$, facial hemispasm $(n=1)$ and borreliosis without central nervous affection. Central neurological diseases included normal pressure hydrocephalus $(\mathrm{n}=4)$, Korsakow's syndrome $(\mathrm{n}=1)$, Wilson's disease $(n=1)$, glioblastoma $(n=1)$ and paraneoplastic cerebellar inflammation $(\mathrm{n}=1)$. All patients with cognitive complaints $(\mathrm{n}=14)$ underwent MMSE, none displayed a score below 26. The cognitive impairments of all depressive patients improved after antidepressant medication, except for 1 patient showing persistent visuospatial deficits.

Preanalytical Treatment of CSF for A $\beta$-SDS-PAGE

Immunoblot, $A \beta 1-42$, Tau and $p$-Tau ELISA

The preanalytical handling of all included CSF samples followed a standardized protocol according to previously published data [15].

Briefly, CSF drawn from patients by lumbar puncture was sampled in polypropylene vials and centrifuged $(1,000 \mathrm{~g}, 10 \mathrm{~min}$, $4^{\circ} \mathrm{C}$ ). Aliquots of $200 \mu \mathrm{l}$ were kept at room temperature for a maximum of $24 \mathrm{~h}$ before storage at $-80^{\circ} \mathrm{C}$ for subsequent $\mathrm{A} \beta$-SDSPAGE/immunoblot (amyloid beta sodium dodecyl sulphate polyacrylamide gel electrophoresis with Western immunoblot) analysis and p-tau ELISA, respectively. Freezing of samples was conducted by directly cooling $200 \mu \mathrm{l}$ of CSF in polypropylene cups down to $-80^{\circ} \mathrm{C}$. Neither an intermediate temperature stage nor shock freezing was performed. There was no additional freeze and thaw cycle before analysis.

CSF for A $31-42$ and tau ELISA analysis was stored at $+4^{\circ} \mathrm{C}$ and analyzed within 2 days. There was no impact of storage time before freezing as controlled for up to $48 \mathrm{~h}$ on $\mathrm{A} \beta$ peptide or tau protein levels.

\section{A $\beta$-SDS-PAGE/Immunoblot}

For direct analysis of different $A \beta$ peptide species, $10 \mu \mathrm{l}$ of unconcentrated CSF were boiled in a sample buffer for SDSPAGE, and A $\beta$-SDS-PAGE/immunoblot was conducted as published elsewhere $[15,20]$.

CSF samples of each individual patient were run as triplicates at minimum and each gel carried a 4-step dilution series of the synthetic $A \beta$ peptides $A \beta 1-37, A \beta 1-38, A \beta 1-39, A \beta 1-40$ and $A \beta 1-42$. Synthetic peptides $A \beta 1-38, A \beta 1-40$ and $A \beta 1-42$ were obtained from Bachem (Bubendorf, Switzerland), A $\beta 1-37$ and 
Table 1. Absolute abundances of tau and p-tau181, absolute and relative abundances of A $\beta$ peptides in the CSF of the diagnostic groups

\begin{tabular}{|c|c|c|c|c|c|}
\hline Diagnosis & $\begin{array}{l}\text { NDC } \\
(n=30)\end{array}$ & $\begin{array}{l}\mathrm{AD} \\
(\mathrm{n}=30)\end{array}$ & $\begin{array}{l}\text { AD with CVD } \\
(\mathrm{n}=15)\end{array}$ & $\begin{array}{l}\text { Possible VAD } \\
(\mathrm{n}=16)\end{array}$ & $\begin{array}{l}\text { Probable VAD } \\
(\mathrm{n}=21)\end{array}$ \\
\hline Age, years & $64.27 \pm 9.34$ & $72.10 \pm 9.38$ & $68.87 \pm 6.05$ & $74.00 \pm 6.42$ & $70.10 \pm 6.87$ \\
\hline MMSE & $28.76 \pm 1.15$ & $21.19 \pm 4.94$ & $19.15 \pm 7.74$ & $20.38 \pm 4.93$ & $18.64 \pm 8.15$ \\
\hline Tau, ng/ml & $0.267 \pm 0.220$ & $0.591 \pm 0.237$ & $0.726 \pm 0.565$ & $0.393 \pm 0.271$ & $0.473 \pm 0.356$ \\
\hline $\mathrm{p}$-tau, ng/ml & $0.041 \pm 0.020$ & $0.091 \pm 0.025$ & $0.105 \pm 0.062$ & $0.049 \pm 0.024$ & $0.038 \pm 0.014$ \\
\hline $\mathrm{A} \beta 1-42$ ELISA, $\mathrm{ng} / \mathrm{ml}$ & $0.734 \pm 0.324$ & $0.437 \pm 0.128$ & $0.389 \pm 0.179$ & $0.368 \pm 0.175$ & $0.461 \pm 0.252$ \\
\hline $\mathrm{A} \beta 1-37, \mathrm{ng} / \mathrm{ml}$ & $0.997 \pm 0.497$ & $1.050 \pm 0.496$ & $1.236 \pm 0.538$ & $0.769 \pm 0.317$ & $0.747 \pm 0.312$ \\
\hline $\mathrm{A} \beta 1-38, \mathrm{ng} / \mathrm{ml}$ & $1.861 \pm 0.685$ & $2.087 \pm 0.612$ & $1.845 \pm 0.581$ & $1.494 \pm 0.710$ & $1.433 \pm 0.640$ \\
\hline $\mathrm{A} \beta 1-39, \mathrm{ng} / \mathrm{ml}$ & $1.140 \pm 0.518$ & $1.318 \pm 0.391$ & $1.329 \pm 0.520$ & $0.890 \pm 0.401$ & $0.922 \pm 0.464$ \\
\hline $\mathrm{A} \beta 1-40, \mathrm{ng} / \mathrm{ml}$ & $8.739 \pm 3.101$ & $8.988 \pm 1.955$ & $7.525 \pm 1.819$ & $6.533 \pm 2.578$ & $6.324 \pm 2.210$ \\
\hline $\mathrm{A} \beta 1-40^{\circ \mathrm{x}}, \mathrm{ng} / \mathrm{ml}$ & $0.077 \pm 0.039$ & $0.154 \pm 0.098$ & $0.135 \pm 0.099$ & $0.126 \pm 0.062$ & $0.096 \pm 0.036$ \\
\hline $\mathrm{A} \beta 1-42, \mathrm{ng} / \mathrm{ml}$ & $1.373 \pm 0.658$ & $0.684 \pm 0.349$ & $0.840 \pm 0.512$ & $0.669 \pm 0.340$ & $1.026 \pm 0.663$ \\
\hline Sum of all analyzed $A \beta$ peptides & $14.19 \pm 5.070$ & $14.28 \pm 3.323$ & $12.91 \pm 3.562$ & $10.48 \pm 4.111$ & $10.55 \pm 4.207$ \\
\hline$A \beta 1-37 \%$ b & $6.916 \pm 1.634$ & $7.085 \pm 2.275$ & $9.235 \pm 2.367$ & $7.317 \pm 1.196$ & $7.047 \pm 0.699$ \\
\hline$A \beta 1-38 \%^{b}$ & $13.19 \pm 2.261$ & $14.52 \pm 1.882$ & $14.22 \pm 1.840$ & $13.94 \pm 2.378$ & $13.46 \pm 1.209$ \\
\hline$A \beta 1-39 \%^{b}$ & $7.941 \pm 1.822$ & $9.202 \pm 1.541$ & $10.1 \pm 1.882$ & $8.443 \pm 1.818$ & $8.533 \pm 1.486$ \\
\hline $\mathrm{A} \beta 1-40 \%^{\mathrm{b}}$ & $61.93 \pm 4.502$ & $63.36 \pm 4.752$ & $59.77 \pm 5.159$ & $62.57 \pm 5.167$ & $60.82 \pm 3.344$ \\
\hline $\mathrm{A} \beta 1-40^{\text {ox }} \% \mathrm{~b}$ & $0.612 \pm 0.371$ & $1.118 \pm 0.693$ & $1.008 \pm 0.528$ & $1.226 \pm 0.434$ & $0.972 \pm 0.378$ \\
\hline $\mathrm{A} \beta 1-42 \%^{\mathrm{b}}$ & $9.414 \pm 2.203$ & $4.711 \pm 1.493$ & $6.341 \pm 2.562$ & $6.506 \pm 2.416$ & $9.163 \pm 2.665$ \\
\hline
\end{tabular}

Values are means $\pm \mathrm{SD}$. ${ }^{\mathrm{a}}$ Total $\mathrm{A} \beta$ peptide concentration. ${ }^{\mathrm{b}}$ Percentage abundance of $\mathrm{A} \beta$ peptides relative to the total A $\beta$ peptide concentration.

A 1-39 were synthesized automatically according to Janek et al. [21]. Standard preparations of synthetic $A \beta$ peptide mixture were created as described previously [15] and bands were quantified from individual blots of each patient relative to this dilution series using a charge-coupled device camera. The detection sensitivity for the $1 \mathrm{E} 8$ in this optimized immunoblot procedure was $0.6 \mathrm{pg}$ $(\mathrm{A} \beta 1-38, A \beta 1-40)$ and $1 \mathrm{pg}(\mathrm{A} \beta 1-37, \mathrm{~A} \beta 1-39, \mathrm{~A} \beta 1-42)$, respectively [15]. The inter- and intra-assay coefficients of variation for 80 as well as for $20 \mathrm{pg}$ of synthetic $A \beta$ peptides were below $10 \%$ $[15,20]$.

ELISA for Tau Protein, $p$-Tau and A $\beta 1-42$

The commercially available assays Innotest hTAU Antigen

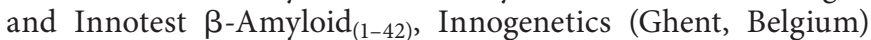
were applied for the quantification of tau protein and $A \beta 1-42$ levels in CSF, respectively. Tau and A $\beta 1-42$ ELISA were performed according to previously published standard methods [22]. The ELISA for tau phosphorylated at Thr181 (p-tau) was conducted as described by Vanmechelen et al. [23]. In brief, the HT7 monoclonal antibody directed against both normal tau and phospho-tau was used as the capturing antibody. The p-tau-specific biotinylated monoclonal antibody AT270 was applied for detection. Otherwise, the same reagents were used as for the Innotest hTAU Antigen.

\section{Statistical Analysis}

Patient groups were characterized by mean and standard deviation. The Mann-Whitney $U$ test was employed for evaluation of significant differences of diagnostic groups (unpaired samples). Comparisons of multiple groups (i.e. age, MMSE) were evaluated by the Kruskal-Wallis test. The Wilcoxon signed rank test was applied for comparative evaluation of test accuracies. The 2sided level of significance was taken as $\mathrm{p}<0.05$. The global diagnostic accuracies were assessed by the area under the receiver operating characteristic curve. Cutoff points were determined at the minimum sensitivity of $85 \%$. The statistical software packages SPSS, version 10.0, and SAS, version 8.2, served for computations.

\section{Results}

\section{Group Differences}

The age did not significantly differ between the dementia diagnostic groups but was lower for the NDC group ( $\mathrm{p}<0.05)$. The MMSE score did neither significantly differ between VAD and AD, nor among the subgroups of VAD ( $\mathrm{p}>0.05)$.

Over all the groups, the regular abundance of $5 \mathrm{~A} \beta$ peptide species aside $\mathrm{A} \beta 1-42$, all carboxyterminally shorter, could be detected. These were the A $\beta$ peptides $A \beta 1-37, A \beta 1-38, A \beta 1-39, A \beta 1-40$ and $A \beta 1-40^{\circ x}$. The latter has just recently been shown to represent an oxi- 


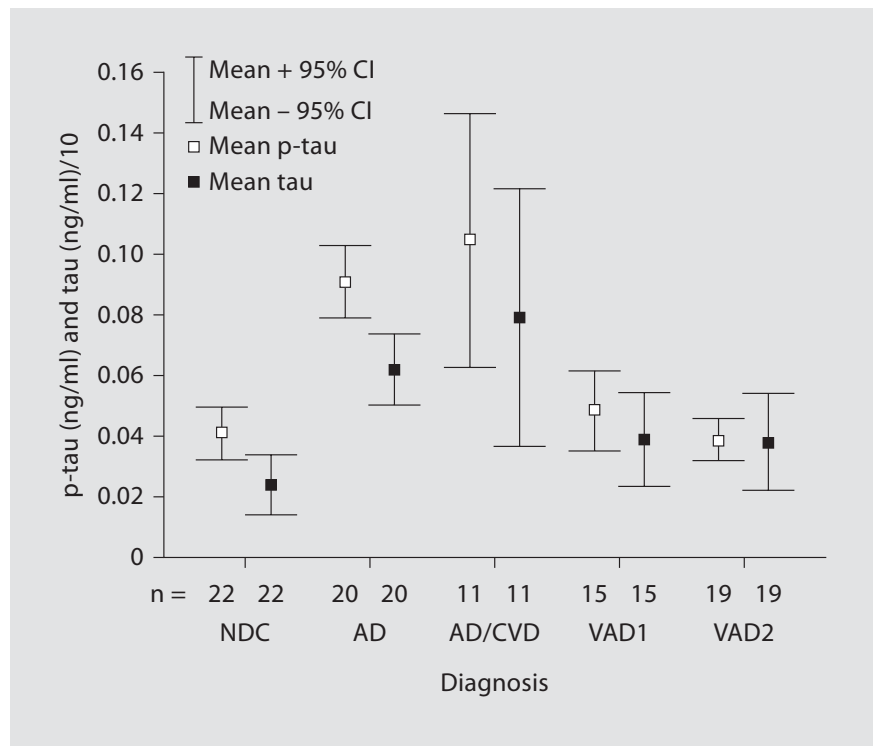

Fig. 1. Mean and $95 \%$ confidence interval (CI) of p-tau181 and total tau for each diagnostic group. VAD1 = Possible VAD; $\mathrm{VAD} 2=$ probable VAD.

dized and potentially $\alpha$-helical coiled form of $A \beta 1-40$ [11].

Among the control group, patients with central neurological diseases exhibited lower absolute levels of $A \beta 1-$ $38, A \beta 1-39$ and $A \beta 1-42$ but an increased percentage abundance of $\mathrm{A} \beta 1-40^{\circ \times} \%$ as compared to peripheral neurological diseases and depressions $(\mathrm{p}<0.05)$.

Table 1 summarizes absolute and relative protein levels. Figures 1 and 2 show the group-specific abundances of tau, $p$-tau and $A \beta 1-40$, respectively. Figure 3 gives the $A \beta 1-42 \%$ values of each diagnostic group.

\section{Neurochemical Phenotype in Probable AD}

As expected, $\mathrm{AD}$ presented with elevated tau and p-tau levels $(p<0.01)$ as compared to NDC. A $\beta 1-42$ was decreased and $A \beta 1-40^{\circ \mathrm{x}}$ was elevated in absolute and percentage terms. In percentage terms, there were additional elevations of $\mathrm{A} \beta 1-38 \%$ and $\mathrm{A} \beta 1-39 \%(\mathrm{p}<$ $0.01)$.

\section{Neurochemical Phenotype in Probable VAD}

Probable VAD displayed lower overall A $\beta$ peptide levels than NDC, except for $A \beta 1-40^{\circ x}$. Accordingly, the $\mathrm{A} \beta 1-40^{\circ \mathrm{ox}} \%$ levels were increased in $\operatorname{VAD}(\mathrm{p}=2.6 \times$ $\left.10^{-3}\right)$. Additionally, the tau $\left(\mathrm{p}=3.3 \times 10^{-2}\right)$ levels and $\mathrm{A} \beta 1-42\left(\mathrm{p}=4.7 \times 10^{-3}\right)$ as measured by ELISA were increased and diminished, respectively.

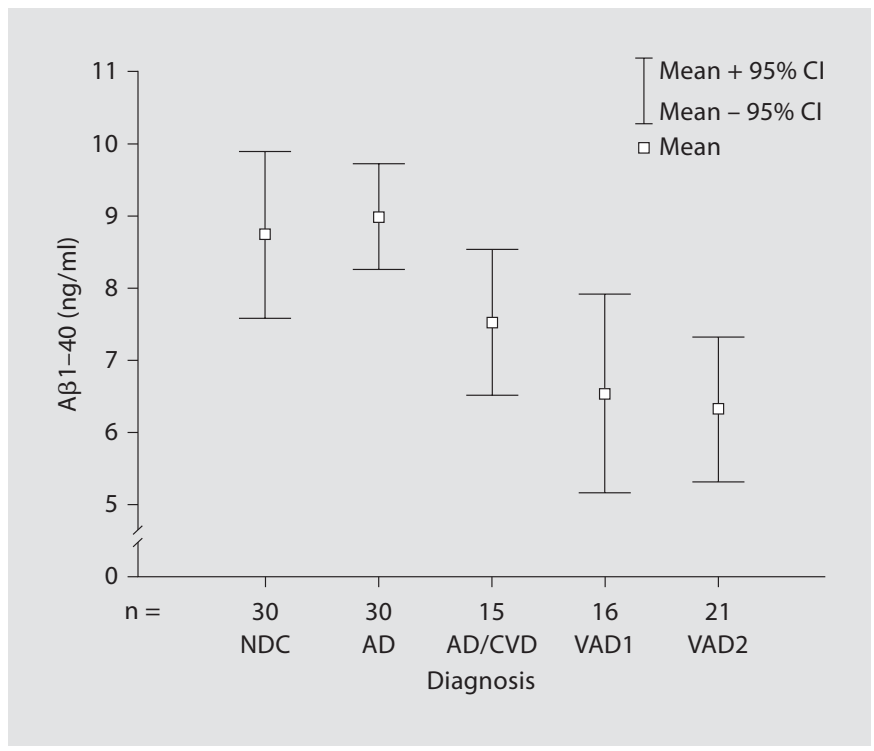

Fig. 2. Mean and $95 \%$ confidence interval (CI) of $A \beta 1-40$ for each diagnostic group. VAD1 = Possible VAD; VAD2 = probable VAD.

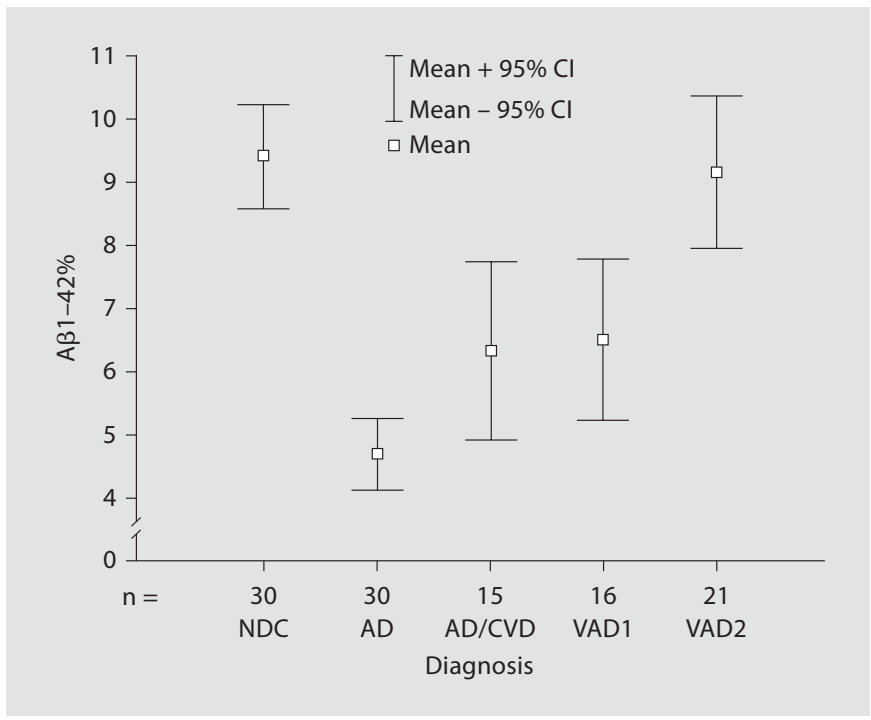

Fig. 3. Mean and $95 \%$ confidence interval (CI) of $A \beta 1-42 \%$ for each diagnostic group. VAD1 = Possible VAD; VAD2 = probable VAD.

Thus, in comparison to $\mathrm{AD}$, there were common alterations in the absolute but not in the percentage $A \beta 1-$ 42 levels, neither were the $\mathrm{p}$-tau levels altered in VAD. It is noteworthy that the $A \beta 1-40$ levels were reduced in probable VAD in absolute $\left(\mathrm{p}=8.7 \times 10^{-5}\right)$ and percent-

Dement Geriatr Cogn Disord 2008;25:256-265 
Table 2. The disease-specific peptide derangements of each diagnostic group in comparison to NDC

\begin{tabular}{|c|c|c|c|c|}
\hline Diagnosis & $\begin{array}{l}\mathrm{AD} \\
(\mathrm{n}=30)\end{array}$ & $\begin{array}{l}\text { AD with CVD } \\
(\mathrm{n}=15)\end{array}$ & $\begin{array}{l}\text { Possible VAD } \\
(\mathrm{n}=16)\end{array}$ & $\begin{array}{l}\text { Probable VAD } \\
(\mathrm{n}=21)\end{array}$ \\
\hline Tau, ng/ml & $\Delta \mathbf{\Delta}^{* *}$ & $\mathbf{\Delta} \mathbf{\Delta}^{* *}$ & & $\mathbf{\Delta}^{*}$ \\
\hline $\mathrm{p}$-tau, ng/ml & $\Delta \mathbf{\Delta}^{* *}$ & $\Delta \mathbf{\Delta}^{* *}$ & & \\
\hline $\mathrm{A} \beta 1-42$ ELISA, ng/ml & $\nabla \nabla * *$ & $\nabla \nabla * *$ & $\nabla \nabla * *$ & $\nabla \nabla * *$ \\
\hline $\mathrm{A} \beta 1-37, \mathrm{ng} / \mathrm{ml}$ & & & & $\nabla^{*}$ \\
\hline $\mathrm{A} \beta 1-38, \mathrm{ng} / \mathrm{ml}$ & & & & $\nabla^{*}$ \\
\hline \multicolumn{5}{|l|}{$\mathrm{A} \beta 1-39, \mathrm{ng} / \mathrm{ml}$} \\
\hline $\mathrm{A} \beta 1-40, \mathrm{ng} / \mathrm{ml}$ & & & $\nabla \nabla * *$ & $\nabla \nabla * *$ \\
\hline $\mathrm{A} \beta 1-40^{\circ \mathrm{x}}, \mathrm{ng} / \mathrm{ml}$ & $\Delta \mathbf{\Delta}^{* *}$ & $\mathbf{\Delta}^{*}$ & $\mathbf{\Delta} \mathbf{\Delta}^{* *}$ & \\
\hline $\mathrm{A} \beta 1-42, \mathrm{ng} / \mathrm{ml}$ & $\nabla \nabla * *$ & $\nabla \nabla *$ & $\nabla \nabla * *$ & $\nabla *$ \\
\hline Sum of all analyzed $A \beta$ peptides & & & $\nabla \nabla * *$ & $\nabla \nabla * *$ \\
\hline$A \beta 1-37 \%^{\mathrm{b}}$ & & $\mathbf{\Delta} \mathbf{\Delta}^{* *}$ & & \\
\hline$A \beta 1-38 \%^{b}$ & $\boldsymbol{\Delta} \mathbf{\Delta}^{* *}$ & & & \\
\hline$A \beta 1-39 \%^{b}$ & $\mathbf{\Delta} \mathbf{\Delta}^{* *}$ & $\boldsymbol{\Delta} \boldsymbol{\Delta}^{* *}$ & & \\
\hline \multicolumn{5}{|l|}{$A \beta 1-40 \%^{\mathrm{b}}$} \\
\hline $\mathrm{A} \beta 1-40^{\mathrm{ox}} \%{ }^{\mathrm{b}}$ & $\boldsymbol{\Delta} \boldsymbol{\Delta}^{* *}$ & $\boldsymbol{\Delta} \boldsymbol{\Delta}^{* *}$ & $\boldsymbol{\Delta} \boldsymbol{\Delta}^{* *}$ & $\boldsymbol{\Delta} \boldsymbol{\Delta}^{* *}$ \\
\hline $\mathrm{A} \beta 1-42 \%^{\mathrm{b}}$ & $\nabla \nabla * *$ & $\nabla \nabla * *$ & $\nabla \nabla * *$ & \\
\hline
\end{tabular}

$\boldsymbol{\Delta}$ = Increased peptide concentration as compared to NDC; $\nabla=$ decreased peptide concentration as compared to NDC.

${ }^{*} \mathrm{p}=0.05$ : significant difference; ${ }^{* *} \mathrm{p}=0.01$ : significant difference.

age terms $\left(\mathrm{p}=8.3 \times 10^{-3}\right)$. Conversely, both dementias shared elevated levels of $A \beta 1-40^{\text {ox }} \%$ and total tau.

\section{Neurochemical Phenotype in Possible VAD}

In comparison to NDC, possible VAD exhibited lower $A \beta 1-42$ levels in absolute and percentage terms. This was only paralleled by a drop in the absolute $A \beta 1-40$ levels. Conversely, there were elevated levels of $\mathrm{A} \beta 1-40^{\circ \mathrm{ox}} \%(\mathrm{p}=$ $2.7 \times 10^{-5}$ ).

Consequently, $\mathrm{AD}$ and possible VAD shared decreased $\mathrm{A} \beta 1-42 \%$ and elevated $\mathrm{A} \beta 1-40^{\text {ox}} \%$ levels in contrast to elevated p-tau levels only in $\mathrm{AD}$. Likewise in probable VAD, only the absolute but not the percentage levels of $\mathrm{A} \beta 1-40$ were decreased $\left(\mathrm{p}=8.3 \times 10^{-4}\right)$.

Lower $A \beta 1-42 \%$ and higher $A \beta 1-40^{\text {ox }}$ levels in possible VAD were the sole differences to probable VAD.

\section{Neurochemical Phenotype in $A D$ with CVD}

In comparison to NDC, $\mathrm{AD}$ with $\mathrm{CVD}$ displayed $\mathrm{AD}$ like derangements of the peptides tau, $p$-tau, $A \beta 1-42$ and $\mathrm{A} \beta 1-40^{\circ \mathrm{ox}}$. Additionally, there were elevations of $A \beta 1-$ $37 \%\left(\mathrm{p}=2.1 \times 10^{-3}\right)$ and $\mathrm{A} \beta 1-39 \%\left(\mathrm{p}=1.1 \times 10^{-3}\right)$, paralleled by a drop in $A \beta 1-40 \%\left(\mathrm{p}=4.3 \times 10^{-2}\right)$.

The differences between $\mathrm{AD}$ and $\mathrm{AD}$ with CVD included higher levels of $A \beta 1-37 \%\left(p=1.1 \times 10^{-2}\right)$ and
$\mathrm{A} \beta 1-42 \%\left(\mathrm{p}=2.1 \times 10^{-3}\right)$, respectively, in the latter group. Unlike in probable and possible VAD, the $\mathrm{A} \beta 1-40$ levels were unchanged.

$A D$ with CVD shared increased levels of tau and $A \beta 1-$ $40^{\circ \mathrm{ox}} \%$ with probable $\mathrm{VAD}$, but diminished $\mathrm{A} \beta 1-42 \%$ and elevated p-tau in $\mathrm{AD}$ with CVD marked the difference.

$\mathrm{AD}$ with $\mathrm{CVD}$ and possible VAD differed in tau and $\mathrm{p}$ tau levels but exhibited similarities in elevated $A \beta 1-40^{\circ \times} \%$ and reduced absolute and percentage A $\beta 1-42$ levels.

The disease-specific peptide derangements of each diagnostic group in comparison to NDC are given in table 2 .

\section{Detection of $A D$ and $A D$ with $C V D$}

The discrimination of AD from NDC yielded contrasts of beyond $85 \%$ by the use of p-tau, $A \beta 1-42 \%, A \beta 1-38 \%$ and $A \beta 1-40^{\circ \mathrm{x}}$ individually. p-tau exhibited the best accuracy for detection of $\mathrm{AD}$ among all other investigated patients with a sensitivity of $85 \%$ and a specificity of $82 \%$.

Both p-tau and A $\beta 1-42 \%$ yielded contrasts of beyond $85 \%$ for discriminating $\mathrm{AD}$ and $\mathrm{AD}$ with CVD (combined to 1 group) from NDC. p-tau gave the best discrimination with a sensitivity of $87 \%$ at a specificity of $84 \%$ for detection of $\mathrm{AD}$ and $\mathrm{AD}$ with $\mathrm{CVD}$ among all other investigated patients (table 3 , fig. 4 ). 

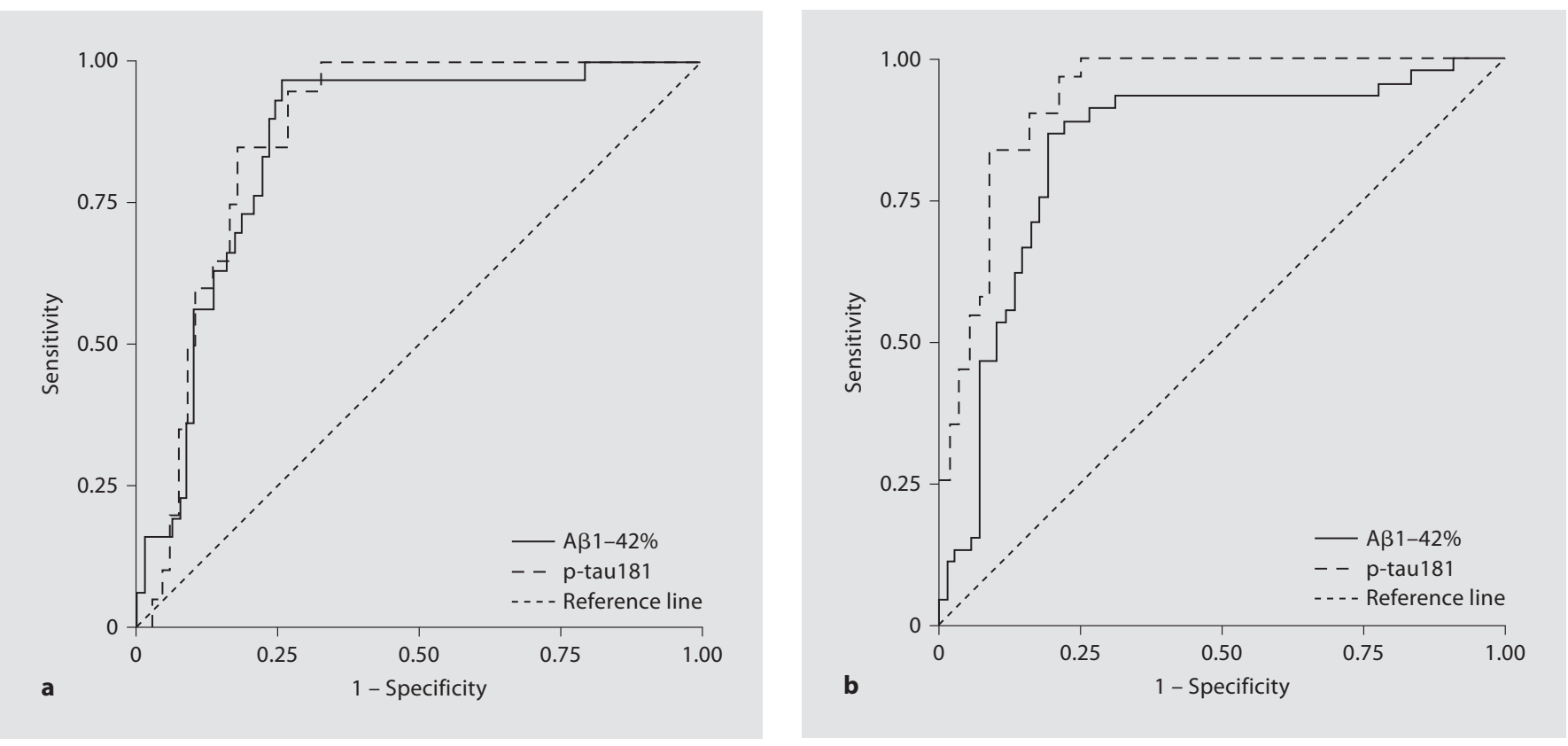

Fig. 4. a Receiver operator curves for detection of $A D$ among all other patients based on $A \beta 1-42 \%$ and $p$-taul 181 . b Receiver operator curves for detection of combined group of AD and AD with CVD among all other patients based on $\mathrm{A} \beta 1-42 \%$ and $\mathrm{p}$-tau181.

Table 3. Cutoff points, sensitivities and specificities for the most relevant differential diagnostic testing

\begin{tabular}{|c|c|c|c|c|c|c|}
\hline Differential diagnosis & Parameter & Cutoff & Sensitivity, \% & Specificity, \% & Youden & AUC \\
\hline \multirow[t]{2}{*}{$\mathrm{AD}$ versus NDC } & $\mathrm{p}$-tau, ng/ml & 0.066 & 85 & 91 & 0.76 & $\begin{array}{l}0.94 \\
(0.87-1.01)\end{array}$ \\
\hline & $\mathrm{A} \beta 1-42 \%$ & 5.85 & 90 & 97 & 0.87 & $\begin{array}{l}0.96 \\
(0.91-1.02)\end{array}$ \\
\hline \multirow[t]{2}{*}{ AD versus all other } & $\mathrm{p}$-tau, ng/ml & 0.069 & 85 & 82 & 0.67 & $\begin{array}{l}0.87 \\
(0.80-0.94)\end{array}$ \\
\hline & $\mathrm{A} \beta 1-42 \%$ & 5.85 & 90 & 77 & 0.67 & $\begin{array}{l}0.86 \\
(0.78-0.93)\end{array}$ \\
\hline \multirow{2}{*}{$\begin{array}{l}A D \text { and } A D \text { with } \\
C V D \text { versus NDC }\end{array}$} & $\mathrm{p}$-tau, ng/ml & 0.056 & 90 & 86 & 0.76 & 0.94 \\
\hline & $\mathrm{A} \beta 1-42 \%$ & 7.15 & 91 & 87 & 0.78 & $\begin{array}{l}0.92 \\
(0.86-0.99)\end{array}$ \\
\hline \multirow{2}{*}{$\begin{array}{l}A D \text { and } A D \text { with } \\
C V D \text { versus all other }\end{array}$} & $\mathrm{p}$-tau, ng/ml & 0.057 & 87 & 84 & 0.71 & 0.93 \\
\hline & $\mathrm{A} \beta 1-42 \%$ & 6.36 & 87 & 81 & 0.68 & $\begin{array}{l}0.84 \\
(0.76-0.92)\end{array}$ \\
\hline
\end{tabular}

Figures in parentheses are 95\% CI. AUC = Area under the receiver operating characteristic curve. 


\section{Discussion and Mini-Review}

Herein, we present first results on the detailed characterization of $A \beta$ species in CSF of VAD subgroups in comparison to $\mathrm{AD}$ and NDC.

The detailed characterization of carboxyterminally shorter $A \beta$ peptides as referenced to $A \beta 1-42$ and oxidized $A \beta$ peptide species (i.e. oxidized $A \beta 1-40$ ) in CSF (A $\beta$ peptide patterns) is a novel approach that has been enabled by a urea-based quantitative A $\beta$-SDS-PAGE/immunoblot $[15,20]$. The data published so far on this issue suggest $A \beta$ peptide patterns to reflect disease-specific interactions of neurodegenerative processes with the $A \beta$ peptide metabolism more adequately than the sole measurement of CSF A $\beta 1-42[11,14,15,24]$.

\section{Biomarker Studies in VAD}

Previous CSF studies have revealed contradictory results about the concentration of the established biomarkers tau, A $\beta 1-42$ and p-tau in VAD and their differential diagnostic value for discrimination from AD. This may be mainly due to the fact that especially VAD are of heterogeneous etiology. Some studies on tau postulate high levels in VAD [25-27], whereas others found tau to be in the normal range [28-30]. In comparison, data on the performance of CSF A $\beta 1-42$ in discriminating between $\mathrm{AD}$ and VAD are limited. A mild to moderate reduction and considerable overlap with $\mathrm{AD}$ has been reported in most of the studies $[22,31,32]$. As reviewed by experts [33], the differential diagnostic power of tau and $A \beta 1-42$ in a definite case was usually found to be limited [10]. The elevated concentration of phosphorylated tau protein in CSF is a relatively new biomarker that is claimed to be closely related to the pathogenic process of $\mathrm{AD}$ and specific to $\mathrm{AD}$, even in contrast to other forms of dementia. Measurement has been performed using ELISA with antibodies capturing specifically distinct phosphorylation sites of the peptide (e.g. Thr181, Thr199, Thr231 and Thr396/404) [34, 35]. Thr181 phosphorylated tau was evaluated for the differential diagnosis of $\mathrm{AD}$ and VAD in a study that found a pronounced increase in $\mathrm{AD}$ as compared to VAD [32]. Due to some overlap of values, there was no sufficient diagnostic discrimination among $\mathrm{AD}$ and VAD. A large comparative CSF study revealed similar accuracies of the ELISAs specific to Thr181, Thr199 and Thr231 in discriminating AD among various other dementias, including VAD [34]. These results suggest the outcome of Thr181 p-tau ELISA in discriminating among $\mathrm{AD}$ and $\mathrm{VAD}$ to be representative of the Thr199 and Thr231 p-tau ELISAs, too. However, an ELI-
SA specificto the phosphorylation site of tau at Thr396/404 enabled contrasts of beyond $85 \%$ sensitivity and specificity for the discrimination of AD from VAD [35].

The presented data of our study reconfirm the majority of the results of others summarized above with regard to tau and absolute A $\beta 1-42$ values. In particular, we found contrasts for tau and $A \beta 1-42$ in discriminating $\mathrm{AD}$ from probable VAD comparable to those of one of the largest community-based studies made up for the establishment of reference values of these biomarkers [31]. Another study included solely subcortical arteriosclerotic encephalopathy following a modified version of the criteria of Bennett et al. [36] that were made up for the clinical diagnosis of Binswanger's disease, for comparison to $\mathrm{AD}$ [30]. Their results for elevated tau and p-tau levels in $\mathrm{AD}$ correspond to our contrasts between $\mathrm{AD}$ and VAD. With regard to $p$-tau, our results for the discrimination of $\mathrm{AD}$ among probable VAD by p-tau181 resemble those from another study that included 20 cases of VAD in comparison to AD and investigated p-tau231 [37]. Likewise, de Jong et al. [38] achieved accuracies of $85 \%$ or beyond when p-tau and A $\beta 1-42$ were applied to the discrimination of $\mathrm{AD}$ and $\mathrm{VAD}$.

The application of the A $\beta$-SDS-PAGE/immunoblot in addition to commercially available ELISAs for tau, p-tau and $A \beta 1-42$ demonstrated that the drop in CSF $A \beta 1-42$ in $\mathrm{AD}$ was selective and paralleled by a percentage increase of carboxyterminally shorter $A \beta$ peptides and the oxidized form of $A \beta 1-40$. It is noteworthy that $\mathrm{AD}$ with CVD and single VAD patients exhibit a CSF neurochemical phenotype with regard to CSF tau, p-tau, $A \beta 1-42$ and $\mathrm{A} \beta 1-40^{\circ \mathrm{ox}}$. From these data, we conclude that CSF neurochemical phenotypes, especially p-tau and A $\beta 1-42$ levels, sufficiently discriminate between probable AD and VAD. In case of no clear-cut clinical appearance (e.g. possible VAD), distinct CSF biomarker constellations may direct the diagnosis towards either AD or VAD. Moreover, the CSF neurochemical phenotype may indicate the involvement of AD-like pathophysiological pathways and the impact of oxidative stress mechanisms in VAD. In this respect, CSF biomarkers may even help predict an individual's benefit from an $\mathrm{AD}$-specific therapeutic strategy, irrespective of whether it may be symptomatic (e.g. acetylcholinesterase inhibitors) or a hopefully forthcoming causative therapy.

\section{Pathophysiological Implications}

It is still under debate whether a dementia syndrome that exhibits clinical features of both CVD (e.g. history of stroke or vascular lesions in magnetic resonance imag- 
ing) and $\mathrm{AD}$ (e.g. gradual progressive dementia) may be caused by a self-containing disease, the so-called mixed $(\mathrm{AD} / \mathrm{VAD})$ dementia.

This hypothesis is underlined by the frequent finding of overlapping Alzheimer-typical lesions and vascular pathology in postmortem neuropathological studies [5, 10]. Rather than simple coincidence, a growing body of evidence points to a causative relationship between the vascular disease and $\mathrm{AD}$. Atherosclerosis, as a major part of vascular disease, is considered to promote higher local concentrations and accumulation of $A \beta$ via an impaired clearance from the brain into the peripheral blood system $[39,40]$. Conversely, AD may support vascular disease by disturbance of cholinergic innervations of cerebral blood vessels $[41,42]$, which are essentially involved in the autonomic regulation of brain blood flow [43]. In addition to deregulated cerebral blood flow, amyloid precursor protein overexpression [44] and amyloid deposition in cerebral blood vessels (cerebral amyloid angiopathy) [40] have been hypothesized to predispose the $\mathrm{AD}$ brain to ischemic injury. Moreover, inflammatory processes and oxidative stress, which are supposed to play a major pathogenic role in $\mathrm{AD}$ and $\mathrm{VAD}$, may be initialized by both intracerebral $A \beta$ accumulation and repeated brain ischemia [44]. This fits in with our finding of elevated absolute $\mathrm{A} \beta 1-40^{\circ \mathrm{x}}$ levels in $\mathrm{AD}, \mathrm{AD}$ with $\mathrm{CVD}$ and possible VAD, but not in probable VAD, as this peptide is considered to represent an oxidized form of A $\beta 1-40$ [11]. In our study, such a mixed (AD/VAD) dementia syndrome may be present in AD with CVD and partly in possible VAD, which is characterized by an AD-like CSF biomarker constellation.

\section{Limitations of the Study}

One major drawback of the presented data is the heterogeneity of the NDC group that includes 7 patients with organic brain disorders aside peripheral neurologic diseases and depressions. For example, patients with normal pressure hydrocephalus might additionally suffer from small vessel disease in deep parts of the brain and a pathogenic overlap with $\mathrm{AD}$ has been hypothesized [45]. This may have subsequently led to an underestimation of diagnostic accuracies for the discrimination of either VAD or $\mathrm{AD}$ among the control group.

A second weakness is the small sample size, especially for VAD subgroups representing a broad spectrum of clinical appearance accompanied by an inhomogeneous neurochemical phenotype, indicating that there may be different subtypes summarized under the diagnosis VAD. We cannot exclude pre-existing forms of dementia, for example due to $\mathrm{AD}$, or cognitive impairment of another kind in patients classified as VAD. Thus, especially the course of disease in patients with possible VAD could supposedly rely on any form of pre-existing dementia, impaired by stroke. Gamaldo et al. [46], for example, found an increased risk of developing dementia after clinically overt stroke in individuals who had mild cognitive impairment prior to the stroke.

The reliability on clinical diagnosis limits our results in consideration of potential misclassification. Pathogenic conclusions that may be drawn from CSF biomarker constellations are also limited due to the lack of neuropathological data. In the present study, none of the clinical diagnoses have been confirmed by autopsy. Therefore, we propose larger and neuropathologically controlled studies on CSF peptide patterns.

In addition, biomarker-controlled therapy studies will have to be arranged to validate the hypothesis that a CSF biomarker constellation may predict the successfulness of $\mathrm{AD}$-specific therapeutic strategies in other dementias. In this context, it will be of particular importance to additionally assess the presence of apolipoprotein 4 alleles, which may influence the clinical course as well as the neurochemical CSF phenotype of dementia patients.

\section{Acknowledgments}

This study was supported by the following grants from the German Federal Ministry of Education and Research: Kompetenznetz Demenzen (01 GI 0420), HBPP-NGFN2 (01 GR 0447) and the Forschungsnetz der Früh- und Differenzialdiagnose der Creutzfeldt-Jakob-Krankheit und der neuen Variante der CJK (01 GI 0301) and by the EU grants cNEUPRO (contract No. LSHMCT-2007-037950), and neuroTAS (contract No. LSHB-CT-2006037953). M.B. was supported by the research program, faculty of medicine, Georg August University Göttingen. The authors would like to thank Sabine Paul, Birgit Otte and Heike Zech for their excellent technical assistance.

\section{References}

1 Chui HC, Victoroff JI, Margolin D, Jagust W, Shankle R, Katzmann R: Criteria for the diagnosis of ischemic vascular dementia proposed by the State of California Alzheimer's Disease Diagnostic and Treatment Centers. Neurology 1992;42:473-480.

2 Roman GC, Tatemichi TK, Erkinjutti T, Cummings JL, Masdeu JC, Garcia JH, Amaducci L, Orgogozo JM, Brun A, Hofmann A: Vascular dementia: diagnostic criteria for research studies - report of the NINDSAIREN International Workshop. Neurology 1993;43:243-245. 
3 McKhann G, Drachman D, Folstein M, Katzmann R, Price D, Stadlan EM: Clinical diagnosis of Alzheimer's disease: report of the NINCDS-ADRDA Work Group under the auspices of Department of Health and Human Services Task Force on Alzheimer's Disease. Neurology 1984;34:939-944.

4 Jellinger KA: Diagnostic accuracy of Alzheimer's disease: a clinicopathological study. Acta Neuropathol 1996;91:219-220.

5 Jellinger KA: The enigma of vascular cognitive disorder and vascular dementia. Acta Neuropathol 2007;113:349-388.

6 Glenner GG, Wong CW: Alzheimer's disease: initial report of the purification and characterization of a novel cerebrovascular amyloid protein. Biochem Biophys Res Commun 1984;120:885-890.

7 Haas C, Selkoe DJ: Cellular processing of beta-amyloid precursor protein and the genesis of amyloid beta-peptide. Cell 1993;75: 1039-1042.

8 Citron M, Diehl TS, Gordon G, Biere AL, Seubert P, Selkoe DJ: Evidence that the 42and 40-amino acid forms of amyloid beta protein are generated from the beta-amyloid precursor protein by different protease activities. Proc Natl Acad Sci USA 1996;93: 13170-13175.

9 Lee VMY, Balin BJ, Otvos L, Trojanowski JQ: A68: a major subunit of paired helical filaments and derivatized forms of normal tau. Science 1991;251:675-678.

10 Blennow K: Cerebrospinal fluid protein biomarkers for Alzheimer's disease. NeuroRx 2004;1:213-225.

11 Bibl M, Mollenhauer B, Esselmann H, Lewczuk P, Klafki HW, Sparbier K, Smirnov A, Cepek L, Trenkwalder C, Rüther E, Kornhuber J, Otto M, Wiltfang J: CSF amyloid- $\beta$ peptides in Alzheimer's disease, dementia with Lewy bodies and Parkinson's disease dementia. Brain 2006;129:1177-1187.

12 Bibl M, Mollenhauer B, Esselmann H, Lewczuk P, Trenkwalder C, Brechlin P, Rüther E, Kornhuber J, Otto M, Wiltfang J: CSF diagnosis of Alzheimer's disease and dementia with Lewy bodies. J Neural Transm 2006; 113:1771-1778.

13 Mollenhauer B, Bibl M, Esselmann H, Steinacker $\mathrm{P}$, Trenkwalder C, Brechlin P, Wiltfang J, Otto M: Selective reduction of amyloid beta42 discriminates Alzheimer's from Huntington's disease: indication for distinct pathological events in amyloid beta peptide aggregation. J Neurol Neurosurg Psychiatry 2006;77:1201-1203.

14 Wiltfang J, Esselmann H, Smirnov A, Bibl M, Cepek L, Steinacker P, Mollenhauer B, Buerger K, Hampel H, Paul S, Neumann M, Maler M, Kornhuber J, Kretzschmar HA, Poser S, Otto M: Beta-amyloid peptides in cerebrospinal fluid of patients with Creutzfeldt-Jakob disease. Ann Neurol 2003; 54:263-267.
15 Bibl M, Esselmann H, Otto M, Lewczuk P, Cepek L, Rüther E, Kornhuber J, Wiltfang J: Cerebrospinal fluid (CSF) amyloid beta (A $\beta)$ peptide patterns in Alzheimer's disease (AD) patients and non-demented controls depend on sample pre-treatment: indication of carrier-mediated epitope masking of $\mathrm{A} \beta$ peptides. Electrophoresis 2004;25:2912-2918.

16 Folstein MF, Folstein SE, McHugh PR: 'Minimental state': a practical method for grading the cognitive state of patients for the clinician. J Psychiatr Res 1975;12:189-198.

17 World Medical Organisation. Declaration of Helsinki. British Medical Journal 1996;313: 1448-1449.

18 Fischer P, Jellinger K, Gatterer G, Danielczyk W: Prospective neuropathological validation of Hachinski's ischaemic score in dementias. J Neurol Neurosurg Psychiatry 1991;54:580-583.

19 O’Brien JT, Erkinjutti T, Reisberg B, Roman G, Savada T, Pantoni L, Bowler JV, Ballard C, DeCarli C, Gorelick PB, Rockwood K, Burns A, Gauthier S, DeKosky ST: Vascular cognitive impairment. Lancet Neurol 2003;2:8997.

20 Wiltfang J, Esselmann H, Bibl M, Smirnov A, Otto M, Paul S, Schmid B, Klafki HW, Maler M, Dyrks T, Bienert M, Beyermann M, Rüther E, Kornhuber J: Highly conserved and disease-specific patterns of carboxyterminally truncated Abeta peptides 1-37/38/39 in addition to 1-40/42 in Alzheimer's disease and patients with chronic neuroinflammation. J Neurochem 2002;81:481-496.

21 Janek K, Rothemund S, Gast K, Beyermann M, Zipper J, Fabian H, Bienert M: Study of the conformational transition of A beta(142) using D-amino acid replacement analogues. Biochemistry 2001;40:5457-5463.

22 Hulstaert F, Blennow K, Ivanoiu A, Schoonderwald HC, Riemenschneider $M$, De Deyn PP, Bancher C, Cras P, Wiltfang J, Mehta PD, Iqbal K, Pottel H, Vanmechelen E, Vanderstichele $\mathrm{H}$ : Improved discrimination of AD-patients using $\beta$-amyloid (1-42) and tau levels in CSF. Neurology 1999;52:15551562.

23 Vanmechelen E, Vanderstichele H, Davidsson P, Van Kerschaver E, Van Der Perre B, Sjögren M, Andreasen N, Blennow K: Quantification of tau phosphorylated at threonine 181 in human cerebrospinal fluid: a sandwich ELISA with a synthetic phosphopeptide for standardization. Neurosci Lett 2000; 285:49-52.

24 Bibl M, Mollenhauer B, Lewczuk P, Esselmann H, Wolf S, Trenkwalder C, Otto M, Stiens G, Rüther E, Kornhuber J, Wiltfang J: Validation of amyloid- $\beta$ peptides in CSF diagnosis of neurodegenerative dementias. Mol Psy 2007;12:671-680.
25 Blennow K, Wallin A, Ågren H, Spenger C, Siegfried J, Vanmechelen E: Tau protein in cerebrospinal fluid: A biochemical diagnostic marker for axonal degeneration in Alzheimer's disease? Mol Chem Neuropathol 1995;26:231-245.

26 Andreasen N, Minthon L, Clarberg A, Davidsson $\mathrm{P}$, Gottfries J, Vanmechelen E, Vanderstichele H, Winblad B, Blennow K: Sensitivity, specificity and stability of CSF t-tau in $\mathrm{AD}$ in a community-based patient sample. Neurology 1999;53:1488-1494.

27 Sjögren M, Minthon L, Davidsson P, Granerus AK, Clarberg A, Vanderstichele $\mathrm{H}$ Vanmechelen E, Wallin A, Blennow K: CSF levels of tau, $\beta$-amyloid1-42 and GAP-43 in frontotemporal dementia, other types of dementia and normal aging. J Neural Transm 2000;107:563-579.

28 Vigo-Pelfrey C, Seubert P, Barbour R, Blomquist C, Lee M, Lee D, Coria F, Chang L, Miller B, Lieberburg I: Elevation of microtubule-associated protein tau in the cerebrospinal fluid of patients with Alzheimer's disease. Neurology 1995;45:788-793.

29 Shoji M, Matsubara E, Kanai M, Watanabe M, Nakamura T, Tomidikoro Y, Shizuka M, Wakabayashi K, Igeta Y, Ikeda Y, Mizushima $\mathrm{K}$, Amari M, Ishiguro K, Kawarabayashi T, Harigaya Y, Okamoto K, Hirai S: Combination assay of CSF tau, A $\beta 1-40$ and $A \beta 1-$ 42(43) as a biochemical marker of Alzheimer's disease. J Neurol Sci 1998;158:134140

30 Sjögren M, Davidsson P, Tullberg M, Minthon L, Wallin A, Wikkelso C, Granerus AK, Vandestichele H, Vanmechelen E, Blennow $\mathrm{K}$ : Both total and hyperphosphorylated tau are increased in Alzheimer's disease. J Neurol Neurosurg Psychiatry 2001;70:624-630.

31 Andreasen N, Minthon L, Davidsson P, Vanmechelen E, Vandestichele H, Winblad B, Blennow K: Evaluation of CSF-tau and CSFA $\beta 42$ as diagnostic markers for Alzheimer disease in clinical practice. Arch Neurol 2001;58:373-379.

32 Nägga K, Gottfries J, Blennow K, Marcusson J: Cerebrospinal fluid phospho-tau, total tau and $\beta$-amyloid1-42 in the differentiation between Alzheimer's disease and vascular dementia. Dement Geriatr Cogn Disord 2003;14:183-190.

33 Andreasen N, Sjögren M, Blennow K: CSF markers for Alzheimer's disease: total tau, phospho-tau and Abeta42. World J Biol Psychiatry 2003;4:147-155.

34 Hampel H, Buerger K, Zinkowski R, Teipel SJ, Goernitz A, Andreasen N, Sjögren M, De Bernardis J, Kerkmann D, Ishiguro K, Ohno $\mathrm{H}$, Vanmechelen E, Vanderstichele H, McCulloch C, Möller HJ, Davies P, Blennow K Measurement of phosphorylated tau epitopes in the differential diagnosis of $\mathrm{Alz}$ heimer's disease - a comparative study. Arch Gen Psychiatry 2004;61:95-102. 
35 Hu YY, He SS, Wang X, Duan QH, GrundkeIqbal I, Iqbal K, Wang J: Levels of nonphosphorylated and phosphorylated tau in cerebrospinal fluid of Alzheimer's disease patients: An ultrasensitive bienzyme-substrate-recycle enzyme-linked immunosorbent assay. Am J Pathol 2002;160:12691278 .

36 Bennett DA, Wilson RS, Gilley DW, Fox JH: Clinical diagnosis of Binswanger's disease. J Neurol Neurosurg Psychiatry 1990;53:961965.

37 Buerger K, Zinkowski R, Teipel SJ, Tapiola T, Hiroyuko A, Blennow K, Andreasen N, Hofmann-Kiefer K, DeBernardis J, Kerkmann D, McCulloch C, Kohnken R, Padberg F, Pirttilä T, Schapiro MB, Rapoport SL, Möller HJ, Davies P, Hampel H: Differential diagnosis of Alzheimer disease with cerebrospinal fluid levels of tau protein phosphorylated at threonine 231. Arch Neurol 2002;52:12671272
38 De Jong D, Jansen RW, Kremer BP, Verbeek MM: Cerebrospinal fluid amyloid beta42/ phosphorylated tau ratio discriminated between Alzheimer's disease and vascular dementia. J Gerontol A Biol Sci Med Sci 2006; 61:755-758.

39 De la Torre JC: Alzheimer's disease as a vascular disorder: nosological evidence. Stroke 2002;33:1152-1162.

40 Weller RO, Cohen NR, Nicoll JAR: Cerebrovascular disease and the pathophysiology of Alzheimer's disease: implications for therapy. Panminerva Med 2005;47:239-251.

41 Sato A, Sato Y, Uchida S: Regulation of regional cerebral blood flow by cholinergic fibers originating in the basal forebrain. Int J Dev Neurosci 2001;19:327-337.
42 Roman GC, Kalaria RN: Vascular determinants of cholinergic deficits in Alzheimer's disease and vascular dementia. Neurobiol Aging 2006;27:1769-1785.

43 Farkas E, Luiten PG: Cerebral microvascular pathology in aging and Alzheimer's disease. Prog Neurobiol 2001;64:575-611.

44 Koistinaho M, Koistinaho J: Interactions between Alzheimer's disease and cerebral ischemia - focus on inflammation. Brain Res Rev 2005;48:240-250.

45 Silverberg GD, Mayo M, Saul T, Rubenstein E, McGuire D: Alzheimer's disease, normalpressure hydrocephalus and senescent changes in CSF circulatory physiology: a hypothesis. Lancet Neurol 2003;2:506-511.

46 Gamaldo A, Moghekar A, Kilada S, Resnick SM, Zondermann AB, O'Brien R: Effect of a clinical stroke on the risk of dementia in a prospective cohort Neurology 2006;67: 1363-1369. 